\title{
Prevalence and Outcome of Preterm Neonates Admitted to Neonatal Unit of a Tertiary Care Center in Western Nepal
}

\author{
Laxman Paudel ${ }^{\mathrm{a}, \mathrm{d}}$ Balkrishna Kalakheti ${ }^{\mathrm{b}, \mathrm{d}}$ Kiran Sharma ${ }^{\mathrm{c}, \mathrm{d}}$
}

\begin{abstract}
:
Introduction: Preterm deliveries contribute to major morbidity and mortality in developing countries. They are a leading cause of admission in neonatal care units. Advances in the management have ensured better survival of preterm births, however cost, care and resource limitations influence the outcome. This study was conducted to determine the prevalence, risk factors, morbidity patterns and outcome of preterm admissions to a neonatal unit of a tertiary care center. Methods: This was a retrospective study where all preterm admissions over a period of two years were evaluated for maternal risk factors and morbidity pattern. Outcome was measured in terms of survival rate and case fatality rate. Mann Whitney U test and Fisher's Exact test were used to see the association between various parameters and clinical outcome. Results: Preterm admissions constituted $16.48 \%$ of all neonatal unit admissions with a male to female ratio of 1.32:1. Common risk factors for preterm births were Prelabour Rupture of Membrane (31.2\%) followed by Hypertensive Disorders in Pregnancy (15.1\%) and Antepartum Hemorrhage (8.6\%). Common morbidities were Sepsis (40.9\%), Jaundice (28\%) and Respiratory Distress Syndrome (RDS) (14\%). Case fatality rate was significantly high in RDS (45.1\%) and perinatal asphyxia (11.1\%). Overall survival rate was $75.26 \%$. Conclusion: Preterm births were an important cause for admissions in neonatal unit. Sepsis, jaundice, RDS and necrotizing enterocolitis were common morbidities observed. Since clinical outcome was related to gestational age, improving antenatal care, timely interventions and early referral of high risk pregnancies to tertiary level centers might improve the survival rate
\end{abstract}

Keywords: Gestational Age, NICU, Preterm neonates, Neonatal Unit

\section{INTRODUCTION:}

World Health Organization (WHO) defines preterm birth as a birth occurring before 37 completed weeks of gestation. Each year 15 million babies are born preterm worldwide and1.1 million infants die due to preterm complications. South Asian and African countries contribute $60 \%$ of world's preterm deliveries and $80 \%$ account for preterm deaths.[1] In Nepal 81,000 preterm babies are born annually and 4,300 children under five years die due to preterm complications.[2] $85 \%$ preterms are born between

\footnotetext{
Submitted: 15 May, 2018

Accepted: 02 December, 2018

Published: 08 December, 2018

a - Lecturer, Department of Paediatrics

b - Associate Professor, Department of Paediatrics

c - Resident, Department of Paediatrics

d - Lumbini Medical College and Teaching Hospital, Pravas, Palpa

Corresponding Author:

Laxman Poudel

e-mail: laxmanpaude18@gmail.com

ORCID: https://orcid.org/0000-0002-8341-0982
}

32-37 weeks of gestation.[2] Cause for prematurity is multifactorial. Major causes include prelabour rupture of membrane (PROM), uteroplacental insufficiency, intrauterine vascular lesions, uterine overdistension and cervical incompetence.[3] Various factors influence successful management of prematurity. Level of antenatal care, gestational age, gender, availability of resources and adequately trained personnel play a role in early diagnosis and management of preterm complications.[4]

Despite good neonatal care, premature deliveries have short term consequences like feeding difficulties, hypothermia, hypoglycemia, respiratory distress syndrome (RDS), jaundice and necrotizing enterocolitis (NEC) while long term consequences include motor disability and cognitive problems.[5] Neonatal intensive care is a major

\section{How to cite this article:}

Paudel L, Kalakheti B, Sharma K. Prevalence and Outcome of Preterm Neonates Admitted to Neonatal Unit of a Tertiary Care Center in Western Nepal. Journal of Lumbini Medical College. 2018;6(2):6 pages. DOI: 10.22502/jlmc.v6i2.218. Epub: 2018 Dec 8. 
factor that ensures survival of preterms. Present study was conducted to determine the prevalence and outcome of preterm neonatal admissions and to identify the risk factors for the same.

\section{METHODS:}

This was a retrospective study carried out in Neonatal Intensive Care Unit (NICU) of Lumbini Medical College, Palpa, which is one of the tertiary centers located in Western Nepal. It is equipped with two ventilators, six radiant warmer beds, one incubator and six cots while Special Care Baby Unit (SCBU) is equipped with two warmer beds, three general beds and four cots. Both units are manned with six pediatricians, five residents and nursing staff.

This study was carried out from January 2018 to March 2018 for a period of three months. During this period, hospital records of all preterm admissions in NICU and SCBU from January 2016 till December 2017 were studied. Ethical approval was taken from Institutional Review Committee, before commencement of the study. Babies delivered at less than 37 completed weeks of gestation were included in the study irrespective of birth weight while those born at or after 37 completed weeks were excluded. All information were retrieved from the hospital records which included gestational age at birth, place of birth, gender, birth weight, risk factors for preterm deliveries and medical problems seen during admission and outcome. Preterm babies were classified based on their gestational age into mild preterm (born between 32 to $<37$ completed weeks), very preterm ( born between 28 to 31 completed weeks) and extremely preterm ( born before 28 completed weeks).[6] Gestational age was calculated using the first day of mother's last menstrual period(LMP).If LMP was uncertain , gestational age was calculated using the modified Ballard score.[7] Clinical diagnosis was made based on criteria set to diagnose the underlying conditions for preterm deliveries. Hypoglycemia was defined as blood sugar level below $50 \mathrm{mg} / \mathrm{dl}$.[8] Sepsis was diagnosed based on clinical suspicion and laboratory values as leukocytosis, band cells and toxic granules in peripheral blood smear and positive C-reactive protein (CRP) and blood culture.[9] RDS was diagnosed based on clinical and radiological evidence once other causes of distress were excluded. NEC was diagnosed based on clinical and Bell staging.[10]Similarly, maternal chorioamnionitis was diagnosed based on maternal pyrexia with passage of foul smelling amniotic fluid.

Data were entered in excel spreadsheet and analyzed using Statistical Package for Social Sciences (SPSS ${ }^{\mathrm{TM}}$ ) version 20. Case fatality rate was calculated and association between birth weight and period of gestation was analyzed. Association between different variables and clinical outcome was seen using Mann Whitney U test and Fisher's Exact test as appropriate. p value less than 0.05 was considered statistically significant.

\section{RESULTS:}

During the study period, 564 neonates were admitted in the neonatal unit of which 93 were preterm. There were 53 males and 40 females with a male to female ratio of 1.32:1 .Seventy one $(76.3 \%)$ were inborn babies while 22 (23.7\%) were outborn. Seventy six $(81.7 \%)$ were hospital deliveries, nine $(9.7 \%)$ were home deliveries, seven (7.5\%) conducted by Trained Birth Attendants (TBA) and remaining one (1.1\%) was unattended deliveries on the way to hospital. Sixty two $(66.7 \%)$ preterms were born via vaginal delivery while $31(33.3 \%)$ by lower segment cesarean section.

Table 1 shows the gestational age wise distribution of preterm deliveries. Mean gestational age $( \pm \mathrm{SD})$ was $31.1 \pm 2.33$ weeks. The most common

Table 1. Gestational Age Wise Distribution of Preterm Neonates ( $n=93$ )

\begin{tabular}{lcc}
\hline Gestational Age & $\begin{array}{c}\text { Frequency } \\
\text { (n) }\end{array}$ & $\begin{array}{c}\text { Percentage } \\
(\%)\end{array}$ \\
$\begin{array}{l}\text { Extremely preterm } \\
\text { < 28 weeks }\end{array}$ & 4 & 4.3 \\
$\begin{array}{l}\text { Very preterm } \\
\text { 28-31completed weeks }\end{array}$ & 27 & 29.0 \\
$\begin{array}{l}\text { Mild preterm 32 -36 } \\
\text { completed weeks }\end{array}$ & 62 & 66.7 \\
Total & 93 & 100.0 \\
\hline
\end{tabular}

gestational age at delivery was 34 weeks $(n=17)$ followed by 36 weeks $(n=16)$. Eighty deliveries were between gestational age of 31 to 36 weeks. Mean birth weight $( \pm \mathrm{SD})$ was $1811.56 \pm 421.064$ grams.

Risk factors for Preterm Births:

The most common risk factor for preterm delivery was PROM (31.2\%) followed by Hypertensive Disorders in Pregnancy (HDP) $(15.1 \%)$ and antepartum haemorrhage (APH) $(8.6 \%)$ 
Table 2. Maternal Risk Factors for Preterm Delivery ( $n=93$ )

\begin{tabular}{|lcc|}
\hline Maternal Risk Factors & $\begin{array}{c}\text { Frequency } \\
\text { (n) }\end{array}$ & $\begin{array}{c}\text { Percentage } \\
(\%)\end{array}$ \\
\hline PROM & 29 & 31.2 \\
\hline Idiopathic & 19 & 20.4 \\
$\begin{array}{l}\text { Hypertensive disorders } \\
\text { in pregnancy }\end{array}$ & 14 & 15.1 \\
\hline $\begin{array}{l}\text { Antepartum } \\
\text { hemorrhage }\end{array}$ & 8 & 8.6 \\
\hline Teenage pregnancy & 6 & 6.5 \\
\hline $\begin{array}{l}\text { Multiple Pregnancy } \\
\text { Previous cesarean } \\
\text { section }\end{array}$ & 5 & 5.4 \\
\hline $\begin{array}{l}\text { Maternal } \\
\text { chorioamnionitis }\end{array}$ & 4 & 4.3 \\
\hline Maternal febrile illness & 2 & 4.3 \\
\hline Rh negative mother & 1 & 2.2 \\
\hline Severe oligohydramnios & 1 & 1.1 \\
\hline Total & 93 & 1.1 \\
\hline
\end{tabular}

as shown in Table 2. Primary diagnosis was only considered in case of maternal risk factors and preterm morbidities. Nineteen deliveries showed no maternal risk factors and were labelled idiopathic.

\section{Morbidity and Mortality Pattern:}

In this study, sepsis was present in $40.9 \%$ followed by jaundice in $28 \%$ and RDS in $14 \%$ cases (Table 3). Though some overlap in the diagnosis was there, only the primary disease was taken as morbidity factor. Case fatality rate was highest in RDS (46.15\%).

\section{Clinical Outcome:}

Mean duration $( \pm \mathrm{SD})$ of hospital stay was $8.86 \pm 6.07$ days. Among 93 neonates admitted, 70 (75.3\%) improved and were discharged, $8(8.6 \%)$ died while $15(16.1 \%)$ were discharged against medical advice. Seventy of the preterms survived with overall survival rate of $75.3 \%$. There was no statistically significant association between mode of delivery and mortality $(p=0.712)$ but low birth weight was significantly associated with mortality $(p=0.0026)$ (Table 4).

\section{Category of Prematurity and Clinical Outcome}

Among 93 preterm babies admitted, 62 (66.7\%) were mild preterm followed by $27(29.0 \%)$ very preterm and remaining $4(4.3 \%)$ were extremely preterm births (Table 1). Excluding those cases which left against medical advice $(n=15)$, statistically

Table 3. Morbidity and Mortality Patterns in Preterm Neonates ( $n=93$ )

\begin{tabular}{|c|c|c|c|c|}
\hline Morbidity & $\begin{array}{l}\text { Frequency } \\
\text { (n) }\end{array}$ & $\begin{array}{c}\text { Percentage } \\
(\%)\end{array}$ & Mortality & $\begin{array}{c}\text { Case Fatality Rate } \\
(\%)\end{array}$ \\
\hline Sepsis & 38 & 40.9 & 1 & 2.63 \\
\hline Jaundice & 26 & 28.0 & 0 & 0.00 \\
\hline Respiratory distress syndrome & 13 & 14.0 & 6 & 46.15 \\
\hline Perinatal asphyxia & 9 & 9.7 & 1 & 11.11 \\
\hline Necrotizing enterocolitis & 2 & 2.2 & 0 & 0.00 \\
\hline Birth defects & 1 & 1.1 & 0 & 0.00 \\
\hline Birth injury & 1 & 1.1 & 0 & 0.00 \\
\hline Hypoglycemia & 1 & 1.1 & 0 & 0.00 \\
\hline Late onset sepsis & 1 & 1.1 & 0 & 0.00 \\
\hline Meconium aspiration syndrome & 1 & 1.1 & 0 & 0.00 \\
\hline Total & 93 & 100.0 & 8 & \\
\hline
\end{tabular}

significant association was found between gestational age and clinical outcome (Table 5). In very preterm category, there was significantly high mortality. On post hoc analysis using Bonferroni correction, adjusted $\mathrm{p}$ value was calculated to be
0.0083. Among the three categories of prematurity, only the extremely preterm category $(p=0.000011)$ was found to be statistically significantly associated with mortality.

Table 4. Association of Birth Weight and Mode of Delivery with Clinical Outcome $(n=78)$

\begin{tabular}{|c|c|c|c|c|}
\hline Variables & & Mortality & Improved & Statistics \\
\hline \multicolumn{2}{|c|}{ Birth weight (gm), Mean \pm SD } & $1466.25 \pm 516.41$ & $1893.43 \pm 415.12$ & Mann Whitney $U=144.500, n=78, p=0.0026$ \\
\hline \multirow{2}{*}{$\begin{array}{l}\text { Mode of } \\
\text { delivery }\end{array}$} & LSCS & 2 & 24 & \multirow{2}{*}{$\mathrm{F}=0.279, \mathrm{n}=78, \mathrm{p}=0.712$} \\
\hline & Vaginal & 6 & 46 & \\
\hline
\end{tabular}


Table 5. Association Between Category of Prematurity and Clinical Outcome $(n=78)$

\begin{tabular}{lccc}
$\begin{array}{l}\text { Prematurity } \\
\text { category }\end{array}$ & \multicolumn{2}{c}{ ClinicalOutcome } \\
Death & Discharged & Statistics \\
$<\mathbf{2 8}$ weeks & 3 & 1 & $\begin{array}{r}\mathrm{F}=12.722, \\
\mathrm{~N}=78, \\
\mathrm{p}=0.001 *\end{array}$ \\
$\mathbf{2 8}-\mathbf{3 1}$ weeks & 3 & 20 & \\
$\mathbf{3 2}-\mathbf{3 6}$ weeks & 2 & 49 & \\
${ }^{*}$ Adjusted $p$ value $=0.0083$ (Bonferroni correction)
\end{tabular}

\section{DISCUSSION:}

Preterm admissions constitute one of the important causes for admissions in NICU. In this study, preterm admissions were $16.4 \%$. This is similar to $14 \%$ of all admissions in a study done by Ankur Gupta et al.[11] and is lower than 24\% in a study done at an institute in Southern Nigeria. [12] Another study done at a teaching hospital in Nigeria showed the rate of preterm admissions to be 16.4\%.[13] The reason for difference in incidence in different studies could be due to geographical and ethnic variations and duration of study.

Studies at various institutes have revealed variable number of preterm male to female ratio among NICU admissions. Our study showed male to female ratio of 1.32:1. Study done by Ankur Gupta et al. [11] showed more preterm females with male to female ratio of $0.84: 1$. In another study by KunleOlowu et al. [12] slightly more preterm males were reported with a male to female ratio of 1.1:1 The reason for more male preterm admissions could be due to special attention and care preferably given to male babies. Due to the social preference of male babies, they are brought more to the hospital for healthcare.

In our study, the most common risk factor for prematurity was PROM followed by HDP and APH. Study by Kuppusamy et al.[14] reported anemia followed by HDP as risk factors for prematurity. This is similar to findings in another study by Chowdarareddy et al.[15] All of these studies have HDP as common risk factor because HDP predisposes to acute and chronic uteroplacental insufficiency leading to antenatal and perinatal hypoxia with adverse outcome as prematurity.[16] Shrestha et al. [17], reported lack of antenatal care as the commonest risk factor for preterm deliveries which is similar to the study by Kunle-Olowu et al.[12] Kuppusamy et al. [14] and Uma et al. [18] from India reported PROM as a major risk factor for prematurity.

The commonest morbidity in the present study was sepsis followed by jaundice and RDS. This is similar to the findings of the study by Shrestha et al.[17] who reported sepsis and jaundice as the commonest morbidities in their preterm infants. Neonatal jaundice followed by RDS and sepsis was the commonest cause for morbidity in other studies.[12,19,20] Respiratory problems followed by jaundice and infection was the most common morbidity reported by Kunle-Olowu et al.[12] This highlights the importance of infection control in management of preterm babies who are at risk of sepsis due to immature immune system. Also there is immediate attention needed to prevent and manage jaundice in these preterm babies.

The case fatality rate was highest in preterms with RDS followed by perinatal asphyxia and sepsis. Shrestha et al.[17] also reported respiratory problems as the commonest cause of death in their preterm infants. Limited intensive facilities and unavailability of exogenous surfactant might be the factors for high mortality in RDS in our center.

The overall survival rate was $75.26 \%$ which increased with increasing gestational age in our study and only one of the four babies born before 28 weeks survived. Survival rate was $95 \%$ in a study by Ankur Gupta et al.[11] and 65.9\% in a study by Kunle-Olowu et al.[12] with survival of only one $(11.1 \%)$ of the nine babies born at less than 28 weeks. Reason for low survival in this institute could be lack of sophisticated diagnostic facilities, inadequate ventilators and inavailability of exogenous surfactants.

\section{LIMITATIONS:}

This study did not assess certain parameters directly linked to maternal risks for preterm deliveries like socio-economic status, cigarette smoking and alcohol consumption, maternal malnutrition and direct trauma to abdomen. Follow up of neonates discharged against medical advice could not be done as well.

\section{CONCLUSION:}

Preterm neonates in our center are one of the contributors of NICU admissions. Sepsis, jaundice and RDS are major causes for admission with PROM as the commonest maternal risk factor. Since clinical outcome is related to gestational age, improving antenatal care, timely interventions and early referral of high risk pregnancies to tertiary 
level centers might improve the survival rate.

\section{Acknowledgement:}

Dr. Susan Thapa and Dr. Sameer Adhikari.

\section{Conflict of interest:}

None Declared.

\section{Financial Disclosure:}

No funds were available.

\section{REFERENCES:}

1. Howson ECP, Kinney MV, Lawn JE. March of Dimes, PMNCH, Save the Children, WHO. Born Too Soon: The Global Action Report on Preterm Birth. [Internet] World Health Organization. Geneva, 2012. Available From: http://www.who.int/pmnch/media/news/2012/201204 borntoosoon-report.pdf

2. US Agency for International Development. Nepal: Profile of preterm and low birth weight prevention and care [Internet]. USAID; 2015. Available from: https://reliefweb. int/sites/reliefweb.int/files/resources/Nepal 2.pdf

3. Butler AS, Behrman RE, editors. Preterm birth: causes, consequences, and prevention. National Academies Press; 2007 May 23. Available from: https://www.ncbi.nlm.nih. gov/books/NBK11362/pdf/Bookshelf NBK11362.pdf

4. Barton L, Hodgman JE, Pavlova Z. Causes of death in the extremely low birth weight infant. Pediatrics. 1999 Feb 1;103(2):446-51. PMID: 9925839 DOI: $10.1542 /$ peds.103.2.446 [ublisher Full Text]

5. Lindström K. Long-term consequences of preterm birth: Swedish National Cohort Studies. Inst för klinisk forskning och utbildning, Södersjukhuset/Dept of Clinical Science and Education, Södersjukhuset; 2011 May 6. [Publisher Full Text]

6. Lumley J. Defining the problem: the epidemiology of preterm birth. BJOG: An International Journal of Obstetrics \& Gynaecology. 2003 Apr;110 Suppl 20:3-7. PMID: 12763104 DOI: 10.1046/j.1471-0528.2003.00011.x [Publisher Full Text]

7. Ballard JL, Novak KK, Driver M. A simplified score for assessment of fetal maturation of newly born infants. The Journal of pediatrics. 1979 Nov 1;95(5):769-74. PMID: 490248

8. Kliegman, R., Stanton, B., St. Geme, J., Schor, N., Behrman, R. and Nelson, W. (2016). Nelson textbook of pediatrics. Philadelphia: Elsevier; 2016. P. 517

9. Kliegman, R., Stanton, B., St. Geme, J., Schor, N., Behrman, R. and Nelson, W. (2016). Nelson textbook of pediatrics. Philadelphia: Elsevier; 2016. P 636-7.

10. Bell MJ, Ternberg JL, Feigin RD, Keating JP, Marshall $\mathrm{R}$, Barton L, Brotherton T. Neonatal necrotizing enterocolitis. Therapeutic decisions based upon clinical staging. Annals of surgery. 1978 Jan;187(1):1-7. PMID: 490248 [Publisher Full Text]

11. Gupta A, Shetty D, Madhava KK. Prevalence and Consequences of Preterm Admissions at the Neonatal Intensive Care Unit of tertiary care centre in South India: a retrospective study. International Journal of Current Advanced Research. 2017 May 28; 06(05):3728-30. DOI: 10.24327/ijcar.2017.3730.0357 [Publisher Full Text]

12. Kunle-Olowu OE, Peterside O, Adeyemi OO. Prevalence and outcome of preterm admissions at the neonatal unit of a tertiary health centre in Southern Nigeria. Open Journal of Pediatrics. 2014 Mar 6;4(01):67. DOI: 10.4236/ ojped.2014.41009 [Publisher Full Text]

13. Ugwu GI. Pattern of morbidity and mortality in the newborn special care unit in a tertiary institution in the Niger Delta region of Nigeria: A two year prospective study. Global Advanced Research Journal of Medicine and Medical Sciences. 2012 Jul;1(6):133-8.

14. Kuppusamy N, Vidhyadevi A. Prevalence of Preterm Admissions and the Risk Factors of Preterm Labor in Rural Medical College Hospital. Int J Sci Stud. 2016 Dec 1;4(9):125-8. DOI: 10.17354/ijss/2016/629 [Publisher Full Text]

15. Chowdareddy N, Kumar YC, Thomas A, Deepthi KU, Ravichander M. Mortality pattern of preterm infants and etiological factors of preterm births in rural tertiary care centre: A retrospective study. International Journal of Scientific and Research Publications. 2014 Mar;4(3):2-3. [Publisher Full Text]

16. Orbach H, Matok I, Gorodischer R, Sheiner E, Daniel S, Wiznitzer A, Koren G, Levy A. Hypertension and antihypertensive drugs in pregnancy and perinatal outcomes. American journal of obstetrics and gynecology. 2013 Apr 1;208(4):301-e1-6. PMID: 23159698 DOI: 10.1016/j.ajog.2012.11.011

17. Shrestha S, Dangol SS, Shrestha M, Shrestha RP. Outcome of preterm babies and associated risk factors in a hospital. Journal of the Nepal Medical Association. 2010 Oct 1;50(180):286-90. PMID: 22049892

18. Uma S, Nisha S, Shikha S. A prospective analysis of etiology and outcome of preterm labor. Journal of Obstetrics and Gynecology of India. 2007 Jan 1;57(1):4852.

19. Onalo R, Olateju KE. Trend and Seasonality in Admissions and Outcome of Low Birth Weight Infants in Gwagalada Abuja, Nigeria. International Journal of Tropical Disease and Health. 2013;3(3):190-8. [Publisher Full Text]

20. Khan MR, Maheshwari PK, Shamim H, Ahmed S, Ali SR. Morbidity pattern of sick hospitalized preterm infants in Karachi, Pakistan. Journal of the Pakistan Medical Association. 2012;62(4):386-88. PMID: 22755286 [Publisher Full Text] 